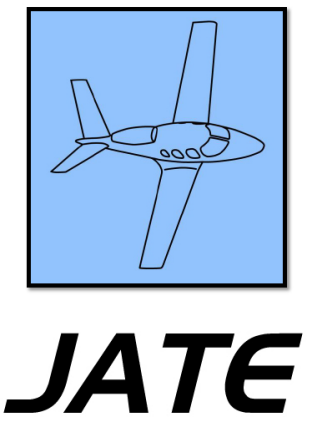

Journal of Aviation Technology and Engineering 5:1 (2015) 7-16

\title{
The Efficacy of Aircraft Type Club Safety
}

\author{
William Jeffrey “Jeff” Edwards
}

Saint Louis University

\begin{abstract}
The FAA and industry are attempting to make significant improvements in general aviation (GA) safety through voluntary measures largely carried out by grassroots aviation organizations, such as aircraft type clubs. While aircraft type clubs are principally focused on safety and education efforts, little is known about the efficacy of their voluntary measures. Research is lacking with respect to understanding whether or not voluntary measures contribute to GA safety. This mixed methods research quantifies the accident data of three aircraft type clubs and compares the safety of their members to nonmembers. A qualitative examination reveals why type club members may have a safer safety record than nonmembers.
\end{abstract}

Keywords: aircraft type clubs, safety, general aviation, general aviation aircraft accidents, efficacy of general aviation safety

\section{Introduction}

On February 2, 2012, an experimental, amateur-built Garza Lancair IV P turbine crashed on takeoff in Boise, Idaho after an uncommanded reduction in engine power, killing the pilot, Mr. Steve Appleton, CEO of Micron, Inc., a Fortune 500 company (See Figure 1). Less than ten minutes prior to the accident takeoff and crash, Mr. Appleton attempted a takeoff, and when the engine made a similar uncommanded reduction to idle, he put the aircraft back down on the runway. He then taxied back and asked the Boise tower controller for another takeoff. Engine data recovered from the accident aircraft and tower audio transcripts were used by the National Transportation Safety Board (NTSB) to reconstruct the sequence of events (National Transportation Safety Board, 2014a).

Mr. Appleton purchased the aircraft approximately one month before the accident. Several individuals recommended Mr. Appleton get type-specific training from the Lancair type club or another approved training provider. Mr. Appleton neither joined the Lancair type club nor obtained specialized training developed for the high-performance aircraft. Lack of

\section{About the Authors}

William Jeffrey "Jeff" Edwards is a doctoral student at Saint Louis University. He is an aircraft accident investigator, flight instructor, and former Navy A-6 bombardier/ navigator. He is founder and president of the Lancair Owners and Builders Organization. He earned his BA from Miami University and his MA from The Ohio State University. His research interest is general aviation safety. Correspondence concerning this article should be sent to vtailjeff@aol.com. 
training and familiarity with the aircraft were cited by the NTSB (2014a) in its report (WPR12FA089) as causal factors in this accident.

Accidents such as Mr. Appleton's are not uncommon in general aviation (GA). GA has an unacceptably high accident rate (about 1 fatal accident per 100,000 flight hours) and was identified as a "most wanted" priority by the NTSB (2014b). Several hundred people per year are killed in GA accidents and many more are injured. The General Aviation Joint Steering Committee (GAJSC), a collaborative effort by the Federal Aviation Administration (FAA) and industry organizations, has been tasked to examine GA accident reports from 2001 to 2010 and to make recommendations to improve GA safety (GAJSC, 2012). The FAA's goal in this effort is a $10 \%$ reduction in the GA accident rate through voluntary measures (GAJSC, 2012). Aircraft type clubs are participants in the industry's efforts to reduce the GA accident rate. They promote GA safety through voluntary measures; however, little is known about the efficacy of these efforts. Thus, reaching the safety goal established by the FAA will be a challenge if the efficacy of "voluntary measures" is not understood.

One barrier to reaching the FAA's safety goal is that many pilots do not participate in voluntary aviation safety programs, such as the aircraft type clubs, FAA Pilot Proficiency Program (also known as the WINGS program), or other voluntary groups, and little is known about why that is so. There is very little information about the safety benefits or efficacy of voluntary aviation safety measures and what those measures might be. Accounting for these issues can help the FAA, NTSB, and the GA industry, such as the Aircraft Owners and Pilots Association (AOPA), the Experimental Aircraft Association (EAA) and aircraft type clubs, to focus their efforts on those pilots at a higher risk of having an accident.

Another barrier to reaching the safety goal is the lack of accident pilot data. The NTSB collects and disseminates very little pilot biographical information, including type club participation for its accident reports, thus data

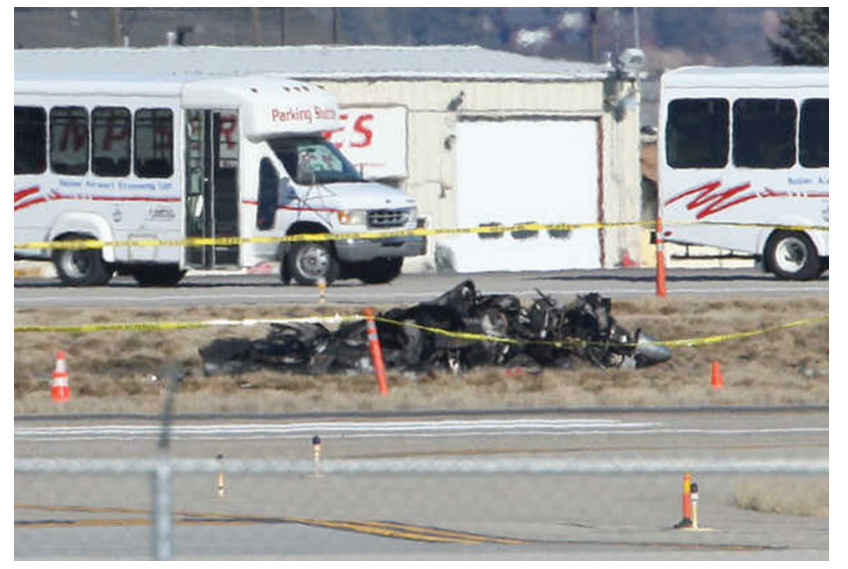

Figure 1. Crash site of N321LC, Garza Lancair IVP-TP (Jaszewski, 2012). collection and analysis of this accident-related data is often absent from its reports. A reduction in GA accidents will be difficult to attain without understanding why pilots like Mr. Appleton do not participate in voluntary organizations such as GA aircraft type clubs, and then are involved in aircraft accidents.

\section{Literature}

Literature related to safety and general aviation was surveyed. There exists a body of literature, discussed below, that examines various aspects of general aviation safety; however, scant literature that specifically addresses the efficacy of safety efforts of aircraft type clubs or aviation affinity groups could be identified. Literature relating to other affinity groups' safety efforts and efficacy was also surveyed with similar results.

Craig (2001) conducted a pilot-centric study and analyzed 2,501 aircraft accidents that occurred from 1983 to 2000 and identified a pilot "killing zone" of total flight time between 50 and 350 hours. Low time in aircraft type, as defined by Craig, accounted for a substantial number of aircraft accidents. Craig also determined that private pilots were more likely to be in an accident than commercial pilots. He attributed this to a lack of experience in new pilots and recommended annual flight reviews for private pilots with less than 400 hours total time.

Li (1994) reviewed epidemiological studies involving pilot error in aircraft accidents. Li's review included studies that examined age, flight experience, vision, medical defects and conditions, alcohol use, occupation, and recent flight time-all showing correlation between these factors and increased chances of an accident. Li and Baker (1994) also studied the correlation between prior accidents and regulatory violations and the likelihood of future accidents by commuter pilots. Their research determined that pilots involved in prior accidents or who had a history of regulatory violations (enforcements) had a 60\% greater chance of having a subsequent accident.

The NTSB (2005) outlined several pilot risk factors in weather-related accidents. Age at first pilot certificate, prior accident history, FAA knowledge test, and practical test failures were identified as aircraft accident risk factors. The NTSB (2012b) also studied Experimental Amateur Built (E-AB) accidents in a yearlong study and incorporated a survey of E-AB pilots, owners, and builders. The NTSB did not address the accident rates of type club members or the effect E-AB type clubs have on safety. The NTSB specifically stated:

The FAA and the EAA, as well as several E-AB aircraft kit manufacturers and aircraft type clubs, strongly encourage specific training for pilots transitioning to $\mathrm{E}-\mathrm{AB}$ aircraft and provide information and resources to support this training. Transition training is needed to 
prepare $\mathrm{E}-\mathrm{AB}$ aircraft pilots for the unique handling characteristics of their aircraft" (NTSB, 2012b, p. 77)

The Lancair Owners and Builders Organization (LOBO) participated with the NTSB in this research.

Hunter (1997) evaluated FAA GA safety programs via survey methodology and found that the private pilot and flight instructor populations were overrepresented. He noted, "one impression held by those who conduct safety seminars was that they "preached to the choir and, for the most part, the same people attended safety seminar repeatedly with little new influx"' (p. 10). Hunter also found that $12 \%$ of his survey population reported belonging to an aircraft owner's club, with 59\% belonging to AOPA. Hunter did not assess the efficacy of the FAA's safety program in reducing GA accidents.

Rakovan, Wiggins, Jensen, and Hunter (1999) also evaluated FAA aviation safety programs via survey methodology. They noted, "Aviation safety seminars presented by the Federal Aviation Administration (FAA) and other groups have been one method of providing safety-oriented information to pilots. However, the effectiveness of such programs may be debated, as voluntary attendance is often low" (p. 1). Rakovan et al. (1999) reported on significant differences between FAA safety program attendees and non-attendees and accident/incident involvement. They found that nonaccident pilots hired certified flight instructors more often than accident pilots. Additionally, their research found that accident pilots reported themselves as higher in knowledge and proficiency than non-accident pilots.

In June 2012, the NTSB hosted a two-day forum on GA safety. "The goals of the forum are: (1) to raise awareness of the GA accident rate and associated recurring safety issue areas; (2) to promote and facilitate dialogue about these issues; and (3) to determine how to effectively address these issues to improve the safety of GA operations for the future" (NTSB, 2012a). Turner's presentation to the forum included data on 1800 American Bonanza Society (ABS) pilots who undertook training in the ABS flight training program. His data showed that from 2000-2005, those pilots had 55\% fewer reportable NTSB mishaps (Turner, 2012a).

Novello and Youssef (1974) and Ferrara's (1994) work identified pilot personality traits from the Edwards Personality Preference Profile (EPPS). These personality traits include: achievement, autonomy, affiliation, intraception, succorance, nurturance, abasement, heterosexuality, dominance, exhibition, change, adventure, deference, order, and endurance. Some of these personality traits may be a barrier to voluntary pilot participation in organizations such as aircraft type clubs.

Kern (1999) analyzed "rogue pilot" issues and defined six common characteristics of rogue pilots that contributed to accidents. These characteristics include social adeptness, dishonesty, superiority complex, differentially motivated, difficult to deal with, and progressive deviation (Kern, 1999). These characteristics also might be barriers to type club participation.

Brandt (1998) compared US Air Force (USAF) aero club accident data and US GA accident data, concluding that, following a 1994 USAF Fly Smart major safety initiative, the USAF club accident rate was significantly lower than GA. Brandt also noted the dissimilarities between the USAF clubs, which relied on internal Air Force policies and regulations to drive safety results, versus voluntary measures such as those found in GA (Brandt, 1998). Brandt's research is instructive, but it indicates that the Air Force flying club safety improvement was the result of nonvoluntary measures. Anecdotal information indicates that while the Air Force was successful in improving safety, the mandatory nature of the policies drove pilots out of the flying clubs as well.

While some research was devoted to identifying factors associated with pilots and accidents, very little research was found regarding the association of affinity or enthusiast groups, such as aircraft type clubs, and accident rates. The Cirrus Owners and Pilots Association (COPA) type club reported on a comparative study of Cirrus accidents involving Cirrus type club members and nonmembers in a January 2010 article. They found that nonmember pilots of Cirrus aircraft were three times more likely to be involved in a fatal accident than members of the type club (Beach, 2010, p. 17)

The FAA conducted research similar to the Cirrus Owners and Pilots Association. The FAA researched accidents involving pilots who participated in a phase of the FAA Aviation Safety Team (FAAST) WINGS program (FAA, 2011b). The quantitative study examined accidents involving pilot participants in the FAAST WINGS program (FAA, 2011b). The FAA examined 3,654 accidents occurring between 2008 and 2010. The research found twenty-five pilots who participated in WINGS incurred an accident during that period. The study was strictly quantitative and noted no reasons why the differences occurred. The study did not compare pilots who did or did not participate in the program to discover themes associated with their findings. The FAA stated:

While it would have been nice to know the number of active General Aviation pilots so that a comparison of some kind could be made, we discovered no meaningful method to determine that number. It should also be pointed out that it was beyond the scope of this study to determine whether it is a pilot's participation in the WINGS Program in and of itself that raises their level of awareness toward risk management, or if the pilots who participate in the WINGS Program already have an effective safety attitude and their participation in the WINGS Program is a natural result of that attitude. (FAA, 2011b, p. 2) 
The purpose of this research is to identify whether or not there are significant differences in accident rates between aircraft type club members and non-type club members. A secondary purpose is to discover why pilots join type clubs and what benefits they receive from the type clubs.

\section{Methodology}

This research utilizes an explanatory mixed methods approach with a concurrent triangulation strategy. The findings were examined for convergence (Creswell, 2009). The mixed methods approach was used because the strength of a quantitative method (generalizability and validity) is complimented by the thick, rich, descriptive analysis of the qualitative method. In other words, the quantitative analysis answers the "what" questions and the qualitative analysis answers the "why" questions.

A quantitative analysis of three aircraft type clubs was performed. A comparison of accidents involving type club members versus non-type club members was performed to determine if there are significant differences in accidents and fatal accidents between groups. Three type clubs were chosen for this study to determine if the results were generalizable and valid. These three type club fleets were comprised of approximately 20,000 aircraft and owner/pilots. A phenomenological qualitative method was also employed to understand why members join type clubs and what safety benefits they realize from their membership. Combining these two methodological approaches provides for a more complete understanding of the phenomena of aircraft type club contributions to GA safety.

Accident data for each aircraft type was obtained from the NTSB via its online database (www.ntsb.gov). Only US accidents were counted. Membership data from type clubs were obtained from each type club and were utilized to determine member versus nonmember status (ABS, 2013; Beach, 2014, personal communication). The non-US-based type club members were excluded from the membership data rosters due to difficulty in obtaining accident data worldwide and in order to harmonize US pilots with US accidents. Finally, accidents involving subject aircraft types were analyzed and compared to membership databases to determine the status of the accident pilot with respect to type club membership. Accident pilots were identified through a variety of sources including matching NTSB report data (date, location) with media reports of the same accidents to identify accident pilot names. This information was then compared to aircraft type club membership information to determine the pilots' membership status. The Cirrus Owners and Pilots Association membership database is available online through its member website access. The American Bonanza Society publishes an annual membership directory, and the Lancair Owners and Builders Organization maintains a membership database. The methodology chosen is similar to the approach utilized in the FAAST safety research.

This research examines differences in accident data involving aircraft type club members and nonmembers, and answers the question, "Are type club members safer than nonmembers as measured by accident data?" Additionally, the research identifies themes present within type clubs that may improve the safety posture of its members. The hypotheses are:

The null hypothesis $\mathrm{H}_{\mathrm{o}}=$ there are no differences in accident rates between the proportion of type club members and non-members.

The alternative hypothesis $\mathrm{H}_{\mathrm{a}}=$ there are differences in accident rates between the proportion of type club members and non-members.

The quantitative research included collecting membership data from three type clubs (LOBO, COPA, and ABS) as well as 2013 NTSB accident data for aircraft represented by the COPA and ABS type clubs and 2009-2013 data for LOBO aircraft. These dates were chosen due to the availability of data.

A qualitative phenomenological study of aircraft type club members and type club leaders is also part of this research. A phenomenological study was performed to determine what factors involving type club membership contribute to aviation safety. Members were interviewed to determine what type club activities contribute to safety and why they participate in type clubs. One part of the qualitative research involved focus groups and questionnaires of LOBO type club members who participated in two training events. Another part involved collecting email responses from type club leaders regarding the efficacy of their type clubs. Type club literature, magazines, and websites were also reviewed to understand and analyze the focus of the aviation groups and to discover common themes across type clubs.

Qualitative research "transports the reader to the setting and gives the discussion an element of shared experience" (Creswell, 2009, p. 19). In keeping with that idea, the researcher traveled to Redmond, Oregon and Charleston, South Carolina and interviewed Lancair pilots at two training events. One event occurred during a LOBO training session in August 2014 at the Lancair thirtieth anniversary fly-in at Redmond, Oregon. The event was comprised of three days of aviation safety presentations by members and experts. Topics included hypoxia, single pilot IFR, test flying new experimental amateur built aircraft, and more. Twenty-nine members of the LOBO type club in one ground school session completed an anonymous questionnaire and participated in a focus group discussion of type club safety. A second cohort of eight Lancair pilots was surveyed and participated in a similar focus group at another Lancair training event in Charleston, South 
Carolina. The researcher was a training instructor for both events.

Finally, leaders of various type clubs and GA organizations who collectively belong to the Type Club Coalition were asked to give their thoughts on type club efficacy via an email request. These questionnaires, field notes, and emails were used in the phenomenological research.

Research questions included:

1) Why do pilots join type clubs?

2) Why do you belong to a type club?

3) Do pilots belong to more than one type club?

4) Have you ever belonged to another type club?

5) Do type club members (you) belong to other aviation organizations?

6) Are pilots who belong to type clubs safer than nonmembers? If so, why?

7) Is that safety benefit measurable and significant?

8) What type club activities foster safety benefits?

9) Do type club members participate in more or less flight training than nonmembers?

10) Do type club members undertake transition and recurrent training more frequently than nonmembers?

\section{Results}

Aircraft type clubs are affinity or enthusiast groups that are typically organizations for aircraft-owner pilots that further the collective interest in and support of a specific aircraft make, model, or design. One prominent goal of the aircraft type clubs is reducing aircraft accidents and improving safety within the fleet. This goal is also shared outside of aviation. A review of similar affinity groups, within the other high-risk recreational activities such as motorcycle groups, alpine climbing clubs, cycling clubs, and SCUBA diving organizations, shows they also have a prominent safety orientation.

There are many aircraft type clubs in the US and around the world. The largest type clubs have nearly 10,000 members and the smallest have less than 100 members. Type clubs typically publish technical information to their membership regarding building (for experimental aircraft), operating, owning, flying, and maintaining the subject aircraft. Type clubs may have a training arm that encourages and supports type-specific flight and ground training for members. For example, the ABS training program was written by a former USAF Thunderbird commander and was frequently attended by an Apollo 13 astronaut. Many type clubs also have annual conventions and social events in order to support training and comradery within the membership. Type clubs may also assist the NTSB and FAA in investigating aircraft accidents involving its fleet as part of their safety focus and advocacy for safety policies and initiatives. Such initiatives have included LOBO's involvement in drafting the FAA Advisory Circular AC 90-109 and advocating for and participating in the drafting of Advisory Circular AC 90-116.

\section{Quantitative Results}

The American Bonanza Society (ABS) is an international aircraft type club that supports the Beech Bonanza (model 33, 35, and 36), Baron (model 55, 56, and 58) and Travel Air (model 95) fleets. The ABS, with nearly 10,000 members around the world, has been in existence since 1967 and has a full-time staff based at its headquarters in Wichita, Kansas, as well as a separate training organization and an aviation safety foundation. The ABS publishes a monthly newsletter oriented to safety, maintenance, and operational information. The ABS has been involved in many safety initiatives on behalf of its fleet and membership, including advocating for common sense solutions concerning proposed airworthiness directives (ADs).

The FAA aircraft registry indicates there are 14,636 (N) US-registered Beech Bonanza, Baron and Travel Airs (FAA, n.d.). This number was used as a surrogate for total fleet pilots, as most of the aircraft are privately owned and not typically operated in flight school or flying club environments. The American Bonanza Society 2013 membership directory (ABS, 2013) was analyzed and found to have 8,842 (n1) US members that year. Thus, 14,463 (N) $-8,842\left(\mathrm{n}_{1}\right)=5,794\left(\mathrm{n}_{2}\right)$ nonmembers. US membership in the American Bonanza society comprised $60.4 \%$ of the active fleet. Accident data was collected for all 2013 Beech Bonanza, Baron, and Travel Air accidents found in the NTSB database. In 2013 there were 49 US accidents involving subject aircraft. US accidents involving US ABS members totaled $12\left(\mathrm{p}_{1}\right)$ of the 49 accidents $(24.5 \%)$. Nonmembers accounted for $37\left(\mathrm{p}_{2}\right)$ accidents $(75.5 \%)$. A two-tailed Z-test was performed, and the results are statistically significant. The Z-score is -5.1506 ; $p$ value is 0 , and the result is significant at $\mathrm{p}<0.05$. Additionally, there were 12 fatal accidents in the fleet in 2013, yet only one (8.3\%) involved an ABS member. The data indicates that for 2013, members of the American Bonanza Society were 2.5 times less likely to have a serious accident and 11 times less likely than nonmembers to be involved in a fatal accident.

The Cirrus Owners and Pilots Association is a not-forprofit organization formed in 2001 and "established to educate, promote the safety of and support the owners and pilots of certified aircraft manufactured by Cirrus Design Corporation" (Cirrus Owners \& Pilots Association, 2014, p. 1). Cirrus accidents from the 2013 calendar year (CY) were analyzed similarly to the ABS data, yielding the following results. There are 4,271 (N) US registered Cirrus SR 20 and SR 22 aircraft (Beach, 2014, personal communication). Most of the fleet is privately owned, although the SR 20 model can be found in small numbers at a few training locations. COPA membership indicates there were 3,125 $\left(\mathrm{n}_{1}\right)$ US members (Beach, 2014, personal communication), for a 
membership market share of $73 \%$ of the fleet. Thus, 4,271 (N) $-3,125$ (n1) $=1,146$ (n2) nonmembers. In 2013, there were 25 US Cirrus accidents with $10\left(\mathrm{p}_{1}\right)$ involving members, or $40 \%$ membership involvement, and 15 involving nonmembers $\left(\mathrm{p}_{2}\right)$. A two-tailed Z-test was performed, and the results are statistically significant. The Z-score is $-3.7538 ; p$ value is 0.00018 and $p<0.05$. Additionally, there were three fatal Cirrus accidents with one member involved (33\%). COPA members were 1.8 times less likely to be involved in an accident than nonmembers and over 2 times less likely to be in a fatal accident.

The Lancair Owners and Builders Organization was formed as a type club in October 2008 to address aviation safety concerns following 17 serious US accidents that year. LOBO's mission statement reads, "The Lancair Owners and Builders Organization (LOBO) promotes the safe use of Lancair Aircraft through education, training and fostering communication between members" (Lancair Owners and Builders Organization, n.d.). The organization currently has nearly 400 members in the US and abroad that own, build, fly, and support the Lancair fleet of aircraft. The FAA aircraft registry indicates there are 1,007 (N) US registered Lancairs (Federal Aviation Administration, n.d.). All Lancairs are experimental amateur built and are privately owned. LOBO membership indicates there were $370\left(n_{1}\right)$ US members in 2013, for $36.7 \%$ of the US fleet (Lancair Owners and Builders Organization, 2014). Thus, 1,007 (N) $-370(\mathrm{n} 1)=637(\mathrm{n} 2)$ non-members. Lancair accident data obtained from the NTSB from 2009 to 2013 (in order to have a larger population size) was examined, yielding 51 reported US accidents with $8\left(\mathrm{p}_{1}\right)(15.7 \%)$ of those accidents involving members. The Z-Score is -3.2012 . The $\mathrm{p}$-value is 0.00138 . The result is significant at $\mathrm{p}<0.05$. Of the 22 Lancair fatal accidents, 4 involved LOBO members (14.8\%) (Lancair Owners and Builders Organization, 2014.

Analysis of the three subject type clubs indicates that type club members are approximately two times less likely to have an accident, and up to eleven times less likely to have a fatal accident. The data suggest that the efficacy of type club safety is generalizable and valid across aircraft type clubs.

\section{Qualitative Results}

A phenomenological study of the aircraft type club safety was examined as part of this mixed methods research. The phenomenological study began in August 2014 and continued through October 2014. Three groups of individuals were interviewed. Research questions were posed to 29 members of the Lancair Owners and Builders Organization who participated at an annual training seminar in August 2014. Questions pertained to certificate level, hours, instrument proficiency checks (IPC), Flight Reviews, FAAST program attendance, type club participation, and other organization participation. Ten additional

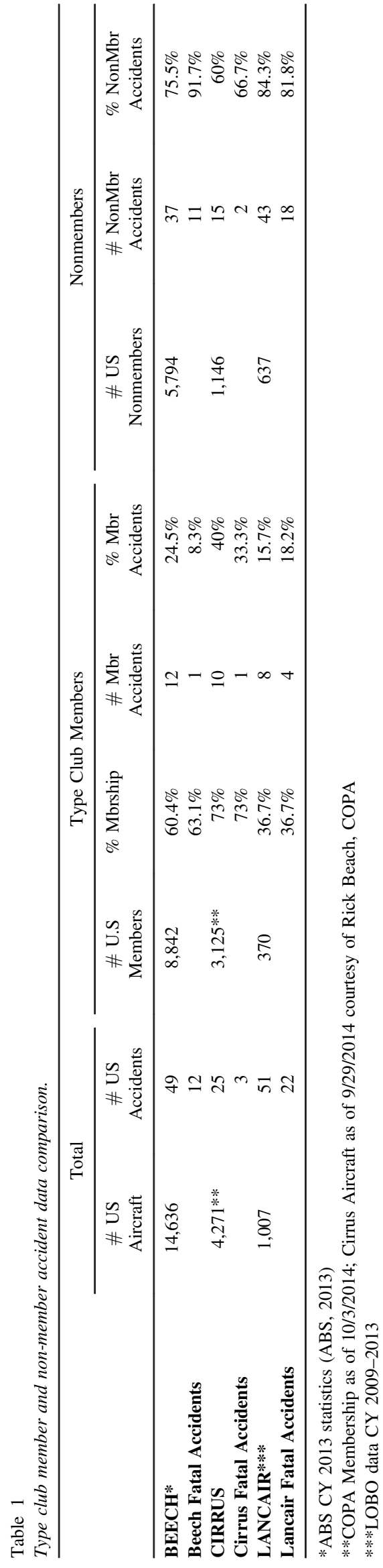


Lancair pilots participated in a focus group in Charleston, South Carolina. Of the 39 pilots, two were student pilots, 19 were private pilots, eight were commercial pilots, six were airline transport pilot (ATP), and four were unknown. The two groups (33 pilots reporting) cumulatively had 148,767 flight hours with a mean of 4,508 flight hours and median of 2,000 hours. In addition to basic pilot flight hour information, pilots were surveyed with the questions found in Appendix A.

Four themes emerged as reasons why members join the type club organization: (1) to share information, (2) to share experiences, (3) learning, and (4) safety. The majority of the attendees responded that they joined the LOBO type club to gain and share information. Thematic words used by the members included "information," "knowledge," "experience," and "safety" (37 out of 39). Underscoring the responses was "share". Members see themselves as contributors to the club's safety goals. Some individual responses included: "share experiences-particularly about maintenance on different models," "LOBO type club great for experience, communication with other owners," "take seminars and learn more and be a safer pilot," and "provides a broad knowledge base on airplanes like mine."

Thirty-seven out of the 39 people asked responded that LOBO was not the first type club to which they have belonged. Other type clubs they have participated in include the Cessna Pilots Association, the Mooney Aircraft Pilots Association, ABS, and others. Thirty-seven of 39 respondents also indicated they belonged to the Aircraft Owners and Pilots Association (AOPA), Experimental Aircraft Association (EAA), and a variety of other aviation organizations.

The attendees overwhelmingly believed that type club members are safer than nonmembers (36 out of 39). Responses to the question about "why" that is so included:

1) "Collective knowledge much more extensive than individual knowledge and experience"

2) "Because of training, because more interested in learning and sharing info. Members have a different attitude/mind set"

3) "Membership indicates interest in safety / competence"

4) "Not sure if this is the cause or effect, club members in general are more safety minded"

5) "Safer pilots join clubs not vice versa. Not the organizations, it's the pilots' personality" "Subset of pilots that join are more safety oriented"

6) "They are safer simply because they show desire to learn more"

Additionally, 13 members of the Type Club Coalition (TCC) who are officers or directors of aircraft type clubs were asked for their thoughts on type club safety. Questions posed to the TCC members are found at Appendix B. Nine respondents believed that their members were safer pilots than nonmembers. Three respondents believed there was no evidence that type clubs were safer. All respondents believed their clubs supported activities that improved safety. Responses included:

- "I believe ABS is making a major difference in the safety of its constituents' ownership and operation. But since our best estimates are that ABS has captured as much as $85 \%$ market penetration in our supported aircraft types, it is very challenging to separate any data we have on members from that of the general population."

- "A recent survey of our membership revealed the same results we've gleaned from surveys before itoverwhelmingly our members join because of ABS Magazine, and $90 \%$ of those who responded indicated they want it to be " $80 \%$ to $90 \%$ " or " $100 \%$ " technical and safety content."

- "We [Commemorative Air Force] have a Safety Management System with all of the elements considered pillars in most models including the dissemination of information, feedback loops, mishap/incident reporting in the clear and autonomously, mishap investigation, management buy in and standards for check rides and qualification (Commercial PTS [practical test standard]). We have reversed the mishap trend of 8-10 years ago by simply using the tools and most importantly, by "in person" presentations/training and opportunities for members to ask questions and feel involved."

- "The Seaplane Pilot Network as a standalone discussion board and networking site for seaplane pilots with a main focus on advocacy and seaplane safety topics. Roughly $85 \%$ of my $600+$ members are aircraft owners, flying anything from a Kitfox to a Marlin Mars in private as well as commercial settings."

When asked, "Do you believe your type club members are safer than non-members?" one respondent stated:

I think belief is irrelevant-I will tell you for a fact that our 900 members would have overwhelmingly answered "yes" a couple of years ago. Then we did a retrospective analysis of fatal accidents over the past 15 years, and for each (where the information was available) verified whether the pilot was a MMOPA member or not at the time of the accident; we were able to determine this for about $80 \%$ of the accidents. There was a "slightly" lower rate of fatals [accidents] for members vs nonmembers, but this didn't come even close to statistical significance. So the only possible conclusion is that membership did not decrease fatal accidents.

This type club did not provide any data for this research and was not the subject of any quantitative research in this study, but future research may include this type club.

The three type club websites were accessed and reviewed. The LOBO website (www.lancairowners.com) 
contains information related to safety, training, and maintenance. The website also has information about upcoming training and social events and assists pilots in locating a Lancair-qualified instructor. The LOBO website also contains back copies of its electronic magazines, or "e-zines." LOBO hosts one annual training event for members during its fly-in. The American Bonanza Society (www.bonanza.org) website has links to similar topics (e.g., safety, training, maintenance, magazine back issues) and also contains sections on tips for buying a Beechcraft. The ABS website has an internal communications forum for members to communicate with each other on ABS topics. The LOBO website does not have such a function, but relies on www.lancairtalk.net for hosted forums. The Cirrus Owners and Pilots Association has a well-developed website (www.cirruspilots.org) that also includes safety, training, and maintenance areas. The COPA website also includes links to weather websites for flight planning and has an internal forum for topic discussion.

In addition to online content, online forums, and magazines, all three type clubs host annual membership events at the Experimental Aircraft Association's Airventure and elsewhere. ABS sponsors a membership tent at Airventure as a gathering place for members. All three type clubs sponsor "fly-ins." The annual "fly-ins" are held at various locations around the country and comprise multiple days of safety-related classes and topics, as well as social events for members to interact. Additionally, COPA sponsors ten Cirrus Pilot Proficiency Programs that offer ground and flight training. The programs are patterned after the ABS Bonanza Pilot Proficiency Program, a flight training program that has been around for over 30 years. COPA also offers a Critical Decision Making (CDM) seminar as well as a European fly-in event.

ABS and COPA both have a full-color magazine that is published monthly for ABS and every other month for COPA. LOBO publishes a quarterly e-zine. Many of the articles in the magazines are written by members or, in the case of the ABS, by staffers and members. The magazine topics mirror the content of the websites.

The COPA Pilot magazine offers Cirrus-specific information on training, safety, and maintenance, as well as information on weather and aeromedical issues. Each month the COPA Pilot magazine interviews and profiles COPA members. Invariably, the member is asked, "why did you join COPA?" In the January 2014 issue, member Kim Blonigen reported that he joined COPA as soon as he bought his first Cirrus after owning an A36 Bonanza and belonging to the ABS (Cirrus Owners \& Pilots Association, 2014). Jim Winner reported that he joined COPA before purchasing an SR 20 and he "visits the [COPA] website daily, and has found the information on the forums to be very beneficial for all aspects of flying, airplane management, and cockpit resources ... [he is] a big believer in learning from someone else's experiences" (Blonigen, 2013, p. 19).

ABS member Kent Ewing wrote about a successful forced landing in his Bonanza after the engine suffered a catastrophic failure last year (Ewing, 2014, p. 22). Cirrus pilot Dr. Richard McGlaughlin similarly suffered an engine failure in his Cirrus SR 22 while flying to the Bahamas. He activated the Cirrus Airframe Parachute System (CAPS $\left.{ }^{(i m}\right)$, and he and his daughter survived a splashdown in the sea. He reported on it extensively on the COPA website, in the COPA magazine, and lectured other pilot members at the COPA get-togethers about the benefit of using the CAPS ${ }^{(i x}$ parachute system. Similarly, a LOBO member reported on an engine failure and forced landing in his Lancair IVP and credited his survival to his LOBO flight training that emphasized emergency engine-out procedures.

Review of type club websites and magazines reveals the focus on safety, training, maintenance, and operations. Type clubs provide information and training to pilots new to an aircraft type in order to make better decisions, resulting in fewer accidents and better outcomes in emergency situations. "What is it about experience that is so valuable? The difference between an experienced pilot and a novice pilot is the quality of the decisions that they make" (Craig, 2001, p. 292). Research indicates type clubs assist pilots by providing information that helps them make better decisions.

\section{Analysis and Conclusions}

This explanatory mixed methods research indicates that aircraft type club members are safer than pilots flying the same type aircraft who do not belong to aircraft type clubs. Convergence triangulation of the qualitative findings indicates type club members are proactive in their approach to aviation safety. The quantitative research indicates the reliability and validity as well as the generalizability to other type clubs. The research indicates that members have a strong need for information as well as a desire to share information related to the operation and maintenance of their aircraft with others. This sharing is evident in their face-to-face participation as well as in the online forums. One aspect of this research that requires further study is to determine whether pilots become safer because they join type clubs, or if safer pilots join type clubs. This cause and effect relationship was not explored in-depth in this research, but the focus groups did comment on that question. They agreed that it is probably a combination of the two. Safer pilots join type clubs and in turn become safer because of their involvement. The three type clubs reviewed here support the members' need for information as well as their desire to be a part of the information sharing process. More research is necessary to understand why nonmembers do not participate in these groups and to find ways to move those pilots into a participatory status, thereby reducing the GA accident rate. 


\section{References}

The American Bonanza Society. (2013). The American Bonanza Society Membership Directory and Buyer's Guide 2013. Wichita, KS: The American Bonanza Society.

Beach, R. (2010, January). Lessons learned from Cirrus accident history: 2009 update. Las Vegas, NV: Cirrus Owners and Pilots Association. Retrieved November 2011, from https://www.cirruspilots.org/copa/ copa_admin/w/admin_pages/747.magazine-preview/revision/33.aspx

Blonigen, K. (2013, November). For the love of aviation. Cirrus Pilot, 8(6), pp. 16-19.

Brandt, K. E. (1998, August). General aviation accidents: The United States Air Force Aero Club solution. Houston, TX: University of Texas Health Science Center at Houston.

Cirrus Owners \& Pilots Association. (2014, January). COPA member guide. Cirrus Pilot, 9(1), p. 1.

Craig, P. A. (2001). The killing zone: How and why pilots die. New York, NY: McGraw-Hill.

Creswell, J. W. (2009). Research design qualitiative, quantitative and mixed methods approaches (3rd ed.). Thousand Oaks, CA: Sage Publications.

Ewing, K. (2014, January). Be prepared. The American Bonanza Society, pp. 22-26. Retrieved from http://www.bonanza.org/MagazinePDF/ 2014/01/201401.pdf

FAA. (n.d.). FAA Registry. Washington, DC: Federal Aviation Administration. Retrieved October 1, 2014, from http://registry.faa.gov/aircraftinquiry/ AcftRef_Inquiry.aspx

FAA. (2011). AC 90-109 Airmen transition to experimental or unfamiliar airplanes. Washington, DC: Federal Aviation Administration.

FAA. (2011, September 15). Report on the Effectiveness of the WINGSPilot Proficiency Program. Washington, DC: Federal Aviation Administration. Retrieved September 28, 2014, https://www. faasafety.gov/files/events/EA/EA03/2012/EA0347223/WINGS_vs_ Accident_Report-Final.pdf

FAA. (2013). US Civil Airmen Statistics. Washington, DC: Federal Aviation Administration. Retrieved October 7, 2014, from https:// www.faa.gov/data_research/aviation_data_statistics/civil_airmen_ statistics/

Ferrara, R. J. (1994). Testing for the existence of the pilot personality profile in collegiate professional pilot candidates. The Journal of Aviation/Aerospace Education \& Research, 4(2). Retrieved from http:// commons.erau.edu/jaaer/vol $4 /$ iss $2 / 9$

GAJSC. (2012). General Aviation Joint Steering Committee Loss of Control Work Group Approach and Landing. Washington, DC: General Aviation Joint Steering Committee.

Hunter, D. R. (1997). An evalutation of safety seminars. Washington, DC: Federal Aviation Administration.

Jaszewski, J. (n.d.). Crash site image. Retrieved from http://www.kboi2. com/news/local/NTSB-preliminary-report-on-Steve-Appleton-planecrash-139083869.html

Kern, T. (1999). Darker shades of blue the rogue pilot. New York, NY: McGraw-Hill.

Lancair Owners and Builders Organization. (n.d.). Retrieved from www. lancairowners.com

Lancair Owners and Builders Organization. (2014, October). Lancair Owners and Builders Membership.

Li, G. (1994). Pilot-related factors in aircraft crashes: A review of epidemiological studies. Aviation, Space, and Environmental Medicine, 944-952.

Li, G., \& Baker, S. (1994). Prior crash and violation records of pilots in commuter and air taxi crashes: A case-control study. Aviation, Space, and Environmental Medicine, 979-985.

Novello, J. R., \& Youssef, Z. (1974, February). Psycho-social studies in general aviation. I. Personality profile of male pilots. Aerospace Medicine, 45(2), pp. 185-188.

NTSB. (n.d.). Aviation Accident Database and Synopses. Retrieved October 1, 2014, from http://www.ntsb.gov/aviationquery/index.aspx
NTSB. (2005). Safety Study Risk Factors Associated With Weather Related General Aviation Accidents (NTSB/SS-05/01). Washington, DC: National Transportation Safety Board.

NTSB. (2010). General Aviation Safety. Retrieved November 2, 2011, from http://www.ntsb.gov/safety/mwl/Pages/mwl-2.aspx

NTSB. (2012a). Forum: General Aviation Safety: Climibing to the Next Level. Retrieved from http://www.ntsb.gov/news/events/Pages/2012 GAS_FRM.aspx

NTSB. (2012b). The Safety of Experimental Amateur-Built Aircraft. Washington, DC: Government Printing Office.

NTSB. (2014a). National Transportation Safety Board Factual Report WPR12FA089. Washington, DC: National Transportation Safety Board. Retrieved September 28, 2014, from http://www.ntsb. gov/about/employment/_layouts/ntsb.aviation/brief2.aspx?ev_ $\mathrm{id}=20120203 \mathrm{X} 23028 \& \mathrm{ntsbno}=\mathrm{WPR} 12 \mathrm{FA0} 089 \&$ akey $=1$

NTSB. (2014b). General Aviation: Identify and Communicate Hazardous Weather. Washington, DC: National Transportation Safety Board. Retrieved September 28, 2014, from http://www.ntsb.gov/safety/mwl/ Pages/mwl7_2014.aspx

Rakovan, L., Wiggins, M. W., Jensen, R. S., \& Hunter, D. R. (1999). A survey of pilots on the dissemination of safety information. Washington, DC: Federal Aviation Administration.

Turner, T. P. (2012a). ABS Air Safety Foundation Beechcraft Pilot Proficiency Program. Washington, DC: National Transportation Safety Board. Retrieved from http://www.ntsb.gov/news/events/Documents/ 2012_GAS_FRM-Pres3a-Turner.pdf

\section{Appendices}

\section{Appendix A: Survey Type Club Members Questions}

1) State pilot certificate held

2) State total flight time

3) Do you take annual flight training?

4) Do you complete an annual IPC?

5) Do you take an annual flight review?

6) Do you complete any special or additional flight training?

7) Do you attend FAAST team WINGS seminars?

8) Did you build your Lancair?

9) Do you do maintenance on your Lancair?

10) Have you taken any engine maintenance courses?

11) Why have a type club?

12) Why did you join a type club?

13) Is this your first type club? Have you belonged to others?

14) What do you get out of this organization (type club)?

15) Do you belong to other aviation organizations? Which ones?

16) When did you first join an aviation organization?

17) Are type club members safer? Why/ why not?

\section{Appendix B: Survey of Type Club Leaders Questions}

1) Do you believe your type club members are safer than non-members?

2) Does your type club promote safe flying practices? How so? 
3) Why do people join your organization? What do they get out of it?

4) Do you publish a magazine or have a website that shares information with members?

5) Do members share information with the organization or is your communication line a one way street?
Does your type club or organization have online training, live training or flight training?

6) Does it sponsor maintenance training?

7) Does your organization advocate to the FAA or other government agencies on aviation safety issues? On other issues important to your membership? 